www.jmscr.igmpublication.org

Impact Factor 5.84

Index Copernicus Value: 83.27

ISSN (e)-2347-176x ISSN (p) 2455-0450

crossref DOI: _https://dx.doi.org/10.18535/jmscr/v5i5.217

Journal Of Medical Science And Clinical Research

\title{
Raised serum CEA and CA 19-9 in Lung Cancer in tertiary care hospital in Eastern India
}

Authors

\section{Ramesh Kumar Sahu ${ }^{1}$, Sanjay Kothari ${ }^{2}$, Pradeep Kumar Agarwal ${ }^{3}$, Vineet Kumar Khemka ${ }^{4}$, Subrata Das ${ }^{5}$, Ravela Malathi ${ }^{6}$}

${ }^{1,2}$ Associate Professor, Dept. of Radiodiagnosis, ICARE Institute of Medical Sciences and Research, Haldia, West Bengal, India

${ }^{3}$ Professor, Dept. of TB \& Chest Medicine, MGM Medical College \& LSK Hospital, Kishanganj, Bihar, India

${ }^{4}$ Assistant Professor, Department of Biochemistry, ICARE Institute of Medical Sciences and Research, Haldia, West Bengal, India

${ }^{5}$ Assistant Professor, Dept. of General Surgery, ICARE Institute of Medical Sciences and Research, Haldia, West Bengal, India

${ }^{6}$ Associate Professor, Department of Biochemistry, ICARE Institute of Medical Sciences and Research, Haldia, West Bengal, India

Corresponding Author

Dr. Sanjay Kothari

Associate Professor, Dept. of Radiodiagnosis, ICARE Institute of Medical Sciences and Research Haldia, West Bengal - 721645. India

Ph: +91-9933300122 (M) Email:skkdoc@gmail.com

\section{ABSTARCT}

Background: Lung cancer is the leading cause of cancer death worldwide. Unfortunately, most lung cancers are already unresectable and metastatic at initial diagnosis. Measurement of tumor markers is a noninvasive means to predict prognosis, and is therefore used in daily clinical practice. Aims \& Objectives: The aim of this study was to assess the diagnostic yield of the tumour markers carcinoembryonic antigen (CEA) and carbohydrate antigen 19-9, in serum and bronchoalveolar lavage fluid in a group of patients with bronchogenic carcinoma.

Materials and Methods: Serum and bronchoalveolar lavage fluid samples were collected in a group of 38 cases with benign or malignant pulmonary diseases and 36 controls. The serum from all the subjects were analyzed for estimation of levels of various tumour markers like CEA and CA 19-9 using enzyme linked immunosorbant assay (ELISA) kits.

Results: Serum CEA level was found significantly higher among lung cancer subjects with respect to controls (28.15 \pm 8.11 versus $5.82 \pm 2.66 \mu \mathrm{g} / \mathrm{L} ; P<0.001)$. Moreover, serum CA 19-9 levels were elevated in lung cancer cases as compared to controls and were statistically significant (60.08 \pm 17.14 versus $23.75 \pm$ 10.58 U/ml; $P<0.001)$. Serum CEA level does not have any correlation with serum CA $19-9(r=$ $0.175 ; P=0.322)$ level among lung cancer subjects as well as in controls $(r=0.075 ; P=0.670)$.

Conclusion: Carcinoembryonic antigen was the most relevant marker in bronchoalveolar lavage fluid. For the factors evaluated in this study, determination of carcinoembryonic antigen and carbohydrate antigen 19- 
9 in bronchoalveolar lavage fluid were clinically more useful markers in comparison with serum, although the latter may also be helpful in certain situations. Although there is no specific tumour marker for lung cancer, the combination of several can be used to diagnose most patients with lung cancer and also to rule out false positive and negative cases.

Keywords: Tumour markers, CEA, CA 19-9, Lung carcinoma, Bronchoalveolar lavage fluid, Serum, ELISA.

\section{INTRODUCTION}

Lung cancer commonly used for tumours arising from the respiratory epithelium (bronchi, bronchioles and alveoli) is the leading cause of cancer death worldwide. According to the World Health Organization classification four major cell types build up $88 \%$ of all primary lung neoplasm. Adenocarcinoma consists of $32 \%$, squamous cell carcinoma $29 \%$, small cell carcinoma $18 \%$ and large cell carcinoma account for $9 \%$ of all cases. ${ }^{[1,2]}$. Despite the improvement in treatment and chemotherapy, the survival rate with advanced lung adenocarcinoma (ALAD) is very poor. ALAD prognosis can be made through various factors, such as pathologic characteristics, imaging features, and oncogenes, but identifycation of more accurate prognostic markers is imperative ${ }^{[1]}$. Emerging technologies for early detection of lung cancer includes low dose helical computed tomography scan, computer aided digital radiography, sputum immunostaining and sputum polymerase chain reaction based oncogene detection, auto fluorescence and virtual bronchoscopy ${ }^{[2-8]}$. Many studies have also chosen mass spectrometry aided secretome analysis in cancer cells for screening purpose ${ }^{[9-12]}$.

Tumor markers are molecules are produced by a tumour associated with a cancer or by the host in response to the cancer whose measurement or identification is useful for clinical diagnosis. It can be used for screening purpose for cancer, making a diagnosis and prognosis better in the course of the disease. Carcinoembryonic antigen (CEA) the first oncofetal antigens consists of a large family of cell surface glycoprotein (molecular weight: $150-300 \mathrm{kDa}$ ) found in many types of cells but associated with tumors and the developing fetus. The normal range is $<2.5 \mu \mathrm{g} / 1$ in an adult nonsmoker and $<5.0 \mu \mathrm{g} / 1$ in a smoker. It is associated with plasma membrane of tumor cells, from which it gets released into the blood. Although CEA was first identified in colon cancer, an elevated CEA level is also found in a variety of cancers like lung, pancreas, gastric, and breast. It is also detected in benign conditions including cirrhosis, inflammatory bowel disease, chronic lung disease, and pancreatitis. On the other hand, Carbohydrate antigen 19-9 (CA19-9) is a monoclonal antibody generated against a colon carcinoma cell line to detect ganglioside found in patients with gastrointestinal adenocarcinoma (molecular weight: $>1,000 \mathrm{kDa}$ ). The upper reference range is $<37 \mathrm{U} / \mathrm{ml}$ in healthy subjects. It is found it to be higher in cases of gastric cancer, lung cancer, colon cancer and pancreatic cancer and has been proposed to differentiate benign from malignant pancreatic disease.

The levels of tumour markers in biological fluids like pleural effusion have been used for screening purpose and diagnosis of pleural malignancy ${ }^{[13,14]}$. This study aims to evaluate the possible role of tumour markers like CEA and CA19-9 in serum of suspected cases in diagnosis of lung cancer.

\section{METHODS}

The case control study was conducted at tertiary care teaching hospital, Haldia, West Bengal, India, during the period of 3 years. The study consists of 38 cases and 36 controls which were age, sex and BMI matched, attending the Chest medicine and General Surgery departments of the hospital. The study was approved by the institutional ethical committee and an informed consent was taken from each subject. Patients with clinicoradiological suspicion of lung malignancy and later confirmed by computed tomography guided fine needle aspiration cytology (FNAC) of peripheral lymph node or fibre optic bronchoscopy (FOB) guided biopsy were considered as cases. Controls were relatives of the patient 
visiting the chest department or routine check up individuals. Patients less than 18 years of age, history of adenocarcinoma of colon, pancreas, breast ovary, hepatocellular carcinoma, pancreastitis, hepatitis, cirrhosis of liver, inflammatory bowel disease and pregnancy were excluded from the study. Serum was separated from $5 \mathrm{ml}$ of venous blood samples collected aseptically from all the cases and controls. The serum from all the subjects were analyzed for estimation of levels of various tumour markers like CEA and CA 19-9 using enzyme linked immunosorbant assay (ELISA) kits. Statistical analysis of different biochemical parameters was performed by Students' $t$-test. All variables were expressed as mean \pm SD (standard deviation). Means obtained from two normally distributed sample groups were compared by Student's unpaired two-tailed " $t$ "-test and for nonparametric Mann-Whitney $U$ " $t$ " test. To find out the correlation between two variables, Pearson's product moment correlation coefficient was used. A value of $P<0.05$ was considered as statistically significant. All statistical analyses were performed by using Graph Pad prism software (version 5, 2007, San Diego, California, USA). Statistical analysis for sex distributions was evaluated by chi-square test by using statistical software STATA (version 8, Copyright 19842003, Stata Corporation, Texas, USA).

\section{RESULTS}

The demographic and biochemical profile of the bronchial asthma subjects and healthy controls is presented in Table 1. There was no significant difference in age, sex distribution or BMI in either of the two groups between lung cancer and control subjects (Table 1). Serum CEA level was found significantly higher among lung cancer subjects (Figure 4,5) with respect to controls (28.15 \pm 8.11 versus $5.82 \pm 2.66 \mu \mathrm{g} / \mathrm{L} ; P<0.001$ ) (Figure 1). Moreover, serum CA 19-9 levels were elevated in lung cancer cases as compared to controls and were statistically significant $(60.08 \pm 17.14$ versus $23.75 \pm 10.58 \mathrm{U} / \mathrm{ml} ; P<0.001$ ) (Figure 2). As presented in Figure 3, serum CEA level does not have any correlation with serum CA 19-9 ( $r=$ $0.175 ; P=0.322)$ level among lung cancer subjects as well as in controls $(r=0.075 ; P=0.670)$.

Table 1: Demographic and biochemical profile of the subjects

\begin{tabular}{|l|c|c|}
\hline & $\begin{array}{c}\text { Control } \\
(\mathrm{n}=36)\end{array}$ & $\begin{array}{c}\text { Lung Cancer } \\
(\mathrm{n}=38)\end{array}$ \\
\hline Age $($ in years $)$ & $54.28 \pm 5.6$ & $55.69 \pm 6.2$ \\
\hline Sex $(\mathrm{M} / \mathrm{F})$ & $28 / 8$ & $30 / 8$ \\
\hline BMI $\left(\mathrm{kg} / \mathrm{m}^{2}\right)$ & $25.67 \pm 2.12$ & $25.96 \pm 2.24$ \\
\hline FPG $(\mathrm{mg} / \mathrm{dl})$ & $89.23 \pm 8.52$ & $88.7 \pm 11.67$ \\
\hline $\begin{array}{l}\text { Serum total } \\
\text { CHL }(\mathrm{mg} / \mathrm{dl})\end{array}$ & $168.5 \pm 22.32$ & $172.8 \pm 32.6$ \\
\hline Serum HDL $(\mathrm{mg} / \mathrm{dl})$ & $42.48 \pm 3.12$ & $41.22 \pm 4.46$ \\
\hline Serum TG $(\mathrm{mg} / \mathrm{dl})$ & $118.4 \pm 23.34$ & $182.8 \pm 89.2^{*}$ \\
\hline
\end{tabular}

[FPG, fasting plasma glucose; CHL, cholesterol; TG, triacylglyceride; HDL, high density lipoprotein cholesterol. Age, BMI, and serum levels of biochemical parameters were expressed as the means \pm SD. Statistically significant, $* \mathrm{p}<$ 0.001 vs Control.]

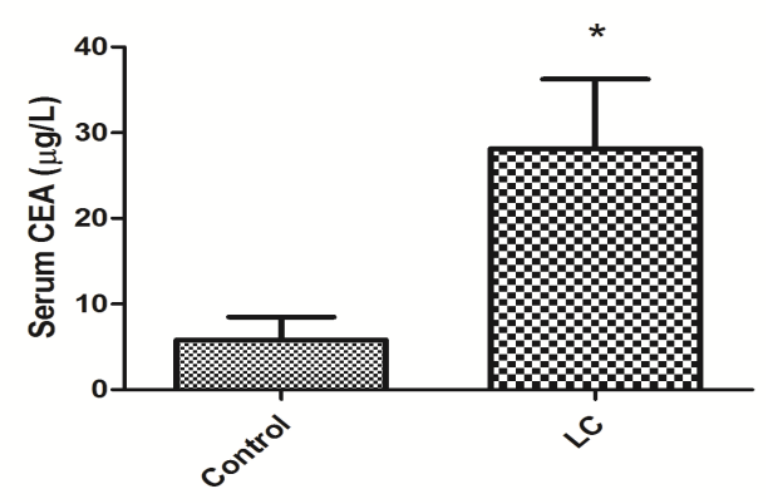

Figure 1: Correlation of serum CEA level among lung cancer subjects with respect to controls $(28.15 \pm 8.11$ versus $5.82 \pm 2.66 \mu \mathrm{g} / \mathrm{L} ; P<0.001)$.

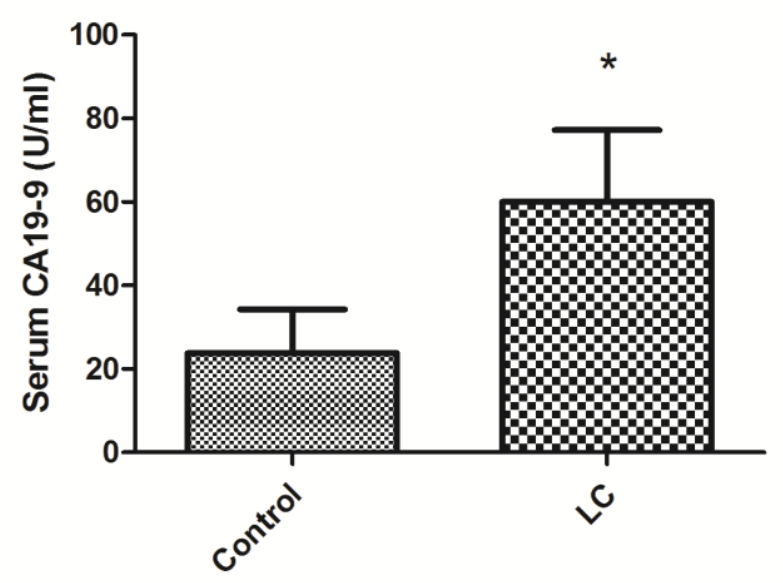

Figure 2: Correlation of serum CA 19-9 levels in lung cancer cases as compared to controls $(60.08$ \pm 17.14 versus $23.75 \pm 10.58 \mathrm{U} / \mathrm{ml} ; P<0.001)$. 

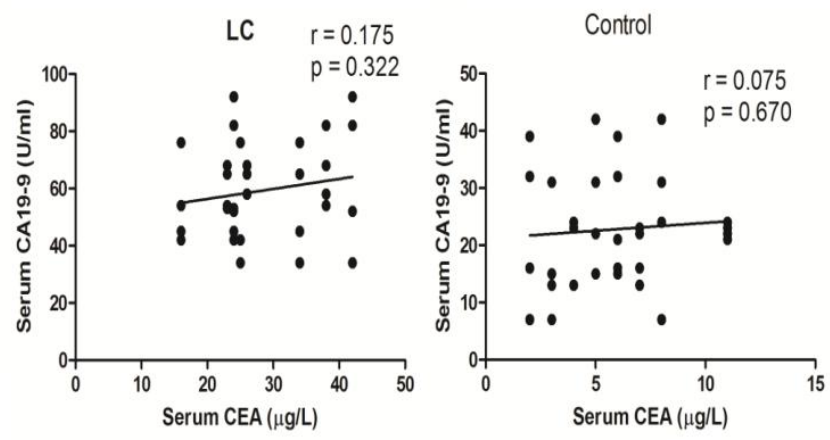

Figure 3: Correlation of serum CEA level with serum CA 19-9 ( $r=0.175 ; P=0.322)$ level among lung cancer subjects as well as in controls $(r=$ $0.075 ; P=0.670$ ).

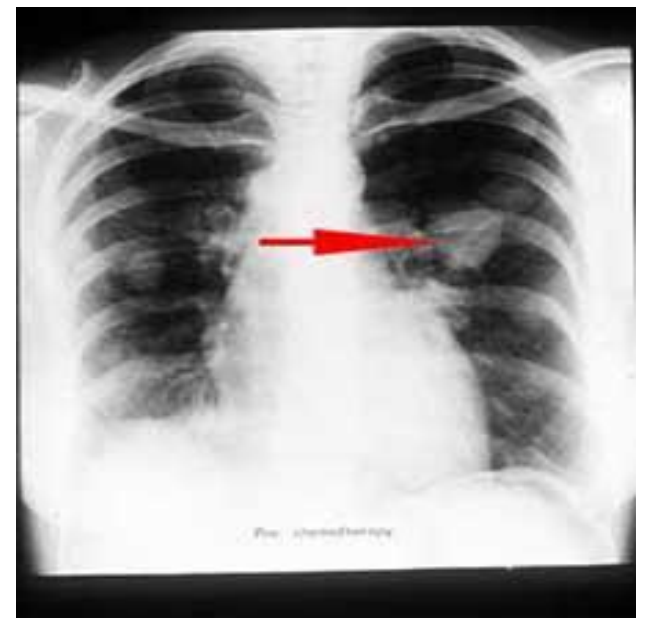

Figure 4: Solitary Pulmonary Nodule on chest Xray

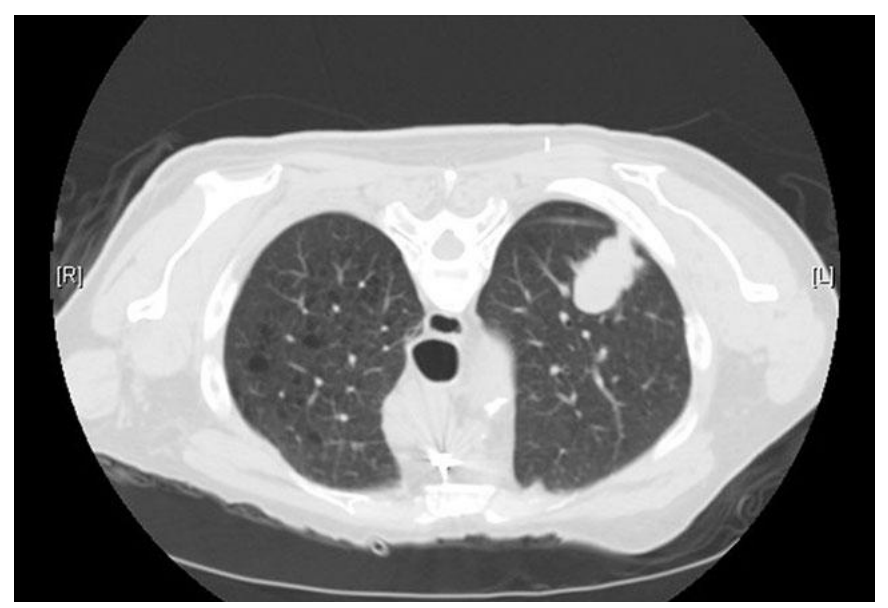

Figure 5: Axial lung window chest CT image from a 62-year-old man, showing solitary pulmonary nodule

\section{DISCUSSION}

In this study we have compared the serum levels of tumour markers such as CEA and CA 19-9 which clearly shows an elevated level in case of lung cancer (Figure 4,5) while compared to controls. Although there was no association between these tumour markers in lung cancer subjects, a significant individual rise was observed which indicates a prognostic marker or screening for the patients before undergoing chemotherapy and overall survival rates. This is in confirmation with a study which showed definite elevation in levels of CEA as well as CA19-9 in both BAL fluid and serum of all the cases compared to the controls. Among the cases, BAL fluid CEA levels are more increased in smokers which indicate that tobacco induces cellular alterations in the bronchial cells among the case group causing increased secretion of CEA. These results are in close agreement with other studies ${ }^{[15]}$. Moreover both age and smoking history are found to manipulate the serum CEA levels ${ }^{[16,17]}$. Four studies also observed that CEA was useful as a predictive marker for risk of recurrence and risk of death measured over time. No studies found CEA levels useful as a diagnostic marker for lung cancer. In one study CEA level was estimated in Pleural Lavage Fluid (PLF) and was found to be useful as prognostic markers for overall survival (OS) after surgery. Thus serum level of CEA carries prognostic and predictive information of risk of recurrence and of death in lung carcinoma [18].

The definite reason for high CA 19-9 levels is not clear but several studies have shown that healthy volunteers did not have high serum CA 19-9 levels which is in confirmation with our study ${ }^{[19}$, ${ }^{20]}$. High CA 19-9 elevation has been observed in some chronic inflammatory lung diseases, such as intestinal pneumonia, bronchiectasis, diffuse panbronchiolitis etc ${ }^{[21]}$. In the present study, CA 19-9 was higher in lung cancer subjects while correlation was not there with CEA and thus it is presumed that elevated serum CA 19-9 was associated with the CA 19-9 generated by cancer 
cells of lung. These findings also indicate that CA 19-9 positive lung adenocarcinoma is highly malignant. We speculate that these malignant features caused the elevated serum CA 19-9 as well as serum CEA, as cancer cell invasion to the blood could cause the elevated serum tumor markers.

Our findings are interesting but there were some limitations to this study. First, as this study was conducted in a single institute with less sample size. Second, some of the associated comorbities associated in patients might interfere because measurement of tumor markers was at the discretion of the attending physician. Third, Lewis antigen status was not examined ${ }^{[22]}$. Patients who are Lewis antigen-negative cannot synthesize CA 19-9, which may produce false negative ${ }^{[23]}$. Despite these limitations there was significant rise in the levels of serum CEA and CA19-9 which indicates that these tumour markers may be used for the screening purpose of the disease. It may also be suggested that these markers may be helpful in diagnosis before and after receiving chemotherapy which may be beneficial in treatment and pathogenesis of the disease.

\section{Acknowledgement}

The authors acknowledge the Director of the institute for their kind support.

Conflict of Interest: None declared.

\section{REFERENCES}

1. John DM, Joan H, et al. Neoplasms of the lung. In: Fauci AS, Braunwald E, Kasper DL, Hanser SL, Longo DL, Jameson JL, et al., editors. Harrison's principles of internal medicine. New York: McGraw Hill; 2008. pp. 2275-2304.

2. Henschke CI, McCauley DI, Yankelevitz DF, Naidich DP, McGuinness G, Miettinen OS, et al. Early lung cancer action project: overall design and findings from baseline screening. Lancet. 1999; 354:99-105.
3. Kobayashi $\mathrm{T}, \mathrm{Xu} \mathrm{XW}$, MacMahon $\mathrm{H}$, Metz CE, Doi K. Effect of a computeraided diagnosis scheme on radiologists' performance in detection of lung nodules on radiographs. Radiology. 1996;199:843848.

4. Kido S, Ikezoe J, Naito H, Arisawa J, Tamura S, Kozuka $\mathrm{T}$, et al. Clinical evaluation of pulmonary nodules with single-exposure dual-energy subtraction chest radiography with an iterative noisereduction algorithm. Radiology. 1995;194:407-412.

5. MacMahon H, Engelmann R, Behlen FM, Hoffmann $\mathrm{KR}$, Ishida $\mathrm{T}$, Roe $\mathrm{C}$, et al. Computer-aided diagnosis of pulmonary nodules: results of a large-scale observer test. Radiology. 1999;213:723-726.

6. Lam S, Shibuya H. Early diagnosis of lung cancer. Clin Chest Med. 1999;20:53-61. doi: 10.1016/S0272-5231(05)70126-X.

7. Sidransky D, Tokino T, Frost P, Hamilton S, Levin B, Vogestein B. Identification of ras oncogene mutations in the stool of patients with curable colorectal tumors. Science. 1992;256:102-105.

8. Sidransky D, Von Eschenbach A, Tsai YC. Identification of p53 gene mutations in bladder cancers and urine samples. Science. 1991;252:706-709.

9. Sung HJ, Cho JY. Biomarkers for the lung cancer diagnosis and their advances in proteomics. BMB Rep. 2008;41:615-625.

10. Andrews CO, Gora ML. Pleural effusions: pathophysiology and management. Ann Pharmacother. 1994;28:894-903.

11. Xiao T, Ying W, Li L, Hu Z, Ma Y, JiaoL, et al. An approach to studying lung cancerrelated proteins in human blood. Mol Cell Proteomics. 2005;4:1480-1486.

12. Chen Y, Zhang H, Xu A, Li N, Liu J, Liu $\mathrm{C}$, et al. Elevation of serum L-lactate dehydrogenase $\mathrm{B}$ correlated with the clinical stage of lung cancer. Lung Cancer. 2006;54:95-102. 
13. Shitrit D, Zingerman B, Shitrit AB, Shlomi D, Kramer MR. Diagnostic value of CYFRA 21-1, CEA, CA 19-9, CA 15-3, and CA 125 assays in pleural effusions: analysis of 116 cases and review of the literature. Oncologist. 2005;10:501-507.

14. Pasaoglu G, Zamani A, Can G, Imecik O. Diagnostic value of CEA, CA-19-9, CA 125 and $\mathrm{CA}$ 15-3 levels in malignant pleural fluids. Eur J Gen Med. 2007;4 (4):165-171.

15. Pardos MC, Alvarez-Sala R, Terreros Caro FJ, Gomez L, de Gomez Terreros FJ, Villamor J. The concentrations of five tumor markers in both BAL fractions in lung cancer patients in relation to cigarette smoking. Tumori. 1999;85(6):454-457.

16. Fukuda I, Yamakado M, Kiyose H. Influence of smoking on serum carcinoembryonic antigen levels in subjects who underwent multiphasic health testing and services. J Med Syst. 1998;22(2):89-93.

17. Alexander JC, Silverman NA, Chretien PB. Effect of age and cigarette smoking on carcinoembryonic antigen levels JAMA. 1976;235(18):1975-1979.

18. Grunnet M, Sorensen JB. Carcinoembryonic antigen (CEA) as tumor marker in lung cancer. Lung Cancer. 2012; 76(2): 138-43.

19. Kim JE, Lee KT, Lee JK, Paik SW, Rhee JC, Choi KW. Clinical usefulness of carbohydrate antigen 19-9 as a screening test for pancreatic cancer in an asymptomatic population. J Gastroenterol Hepatol. 2004;19(2):182-6.

20. Tong Y, Song Z, Zhu W. Study of an elevated carbohydrate antigen 19-9 concentration in a large health check-up cohort in China. Clin Chem Lab Med. 2013;51(7):1459-66.

21. Kodama T, Satoh H, Ishikawa H, Ohtsuka M. Serum levels of CA19-9 in patients with nonmalignant respiratory diseases. $\mathbf{J}$ Clin Lab Anal. 2007;21(2):103-6.

22. Le Pendu J, Marionneau S, CailleauThomas A, Rocher J, Le Moullac-Vaidye $\mathrm{B}$, Clement M. ABH and Lewis histoblood group antigens in cancer APMIS. 2001;109(1):9-31.

23. Vestergaard EM, Hein HO, Meyer $\mathrm{H}$, Grunnet N, Jorgensen J, Wolf H, Orntoft TF. Reference values and biological variation for tumor marker CA 19-9 in serum for different Lewis and secretor genotypes and evaluation of secretor and Lewis genotyping in a Caucasian population. Clin Chem. 1999;45(1):54-61. 